\title{
Research on Resource-based and Theme-oriented College English Teaching
}

\author{
Hong Zhou ${ }^{\mathrm{a}, *}$ \\ ${ }^{a}$ School of Foreign Languages, Wuhan University of Technology, Wuhan, China
}

\begin{abstract}
Guided by the sociocultural theory and input theory, a research was conducted to probe into resource-based and theme-oriented college English teaching. It discusses the principles of college English language materials selection and how theme-oriented teaching activities enhance meaningful language input and output. The results show that the teaching mode can improve students' multiple intelligences on a large scale and facilitate the transformation between students' explicit knowledge and tacit knowledge. Being resource-based and theme-oriented, the mode helps broaden students' horizon, cultivate their humanistic quality, enhance students' information quality and boost the effects of language learning.
\end{abstract}

Index Terms: Theme-oriented College English Teaching; Sociocultural Theory; Resource-based; Input and Output Enhancement; Tacit Knowledge

(C) 2012 Published by MECS Publisher. Selection and/or peer review under responsibility of the International Conference on E-Business System and Education Technology

\section{Introduction}

Second language acquisition has long been the principal business of language teaching research. In college, English language learning should transfer from language form to language knowledge [1]. Vygotsky's sociocultural theory [2], Krashen's input hypothesis [3], Swan's output hypothesis [4] emphasize the great significance of authentic communicative situation and language's meaningful input and output. Now, it is widely recognized that language acquisition cannot go without input, but what kind of input is effective and feasible? How can we organize our teaching to achieve the purpose? After analyzing the related theories and language teaching, the research attempts to design a teaching mode --- resource-based and theme-oriented English teaching, and some measures and suggestions will be discussed.

* Corresponding author.

| E-mail address: hz.1995@163.com 


\section{Theoretical Bases of the Research}

Vygotsky's sociocultural theory of human learning describes learning as a social process and the origination of human intelligence in society or culture. The major theme of Vygotsky's theoretical framework is that social interaction plays a fundamental role in the development of cognition [5]. The theory tells us, in the interactive environment involving society, culture and politics, language learners can become a competent participant through learning. Language acquisition is not only a solitary process of mere recognition but it is social and interactive, which is beyond individual's willingness and actions [6]. VanPatten also states the language teaching should focus on the expression, interpretation and negotiation of meaning; learner should be the center; language learning should use a broad set of materials and should encourage the development of skills; authentic language should be used [7]. Therefore, language teaching should focus on the communicative and interactive environment to enhance the input of massive meaningful material appropriate to learner interests and needs.

According to Krashen, "acquisition takes place as a result of the learner having understood input that is a little beyond the current level of his competence (i.e.the $\mathrm{i}+1$ level). Input that is comprehensible to the learner will automatically be at the right level [8]." Based the theories, creating real social environment and presenting authentic language material in certain interactive situation are the main targets of second language acquisition research. Some activities such as discourse, discussions, collaborative writing, problem-solving, online support systems, should be provided to improve students' evolving understanding and cognitive growth. By the means, not only do students have access to mass authentic language input and output, but also it can help realize the transformation between explicit knowledge and tacit knowledge. They can have more opportunities to cultivate their abilities of communication, information process, making a speech, and edify their moral and sentiments. How does input work from input to intake? Or how can learners acquire language information from input? Bill VanPatten's research shows that language input processing is to make formmeaning connections and parse sentences as in Fig. 1[9].

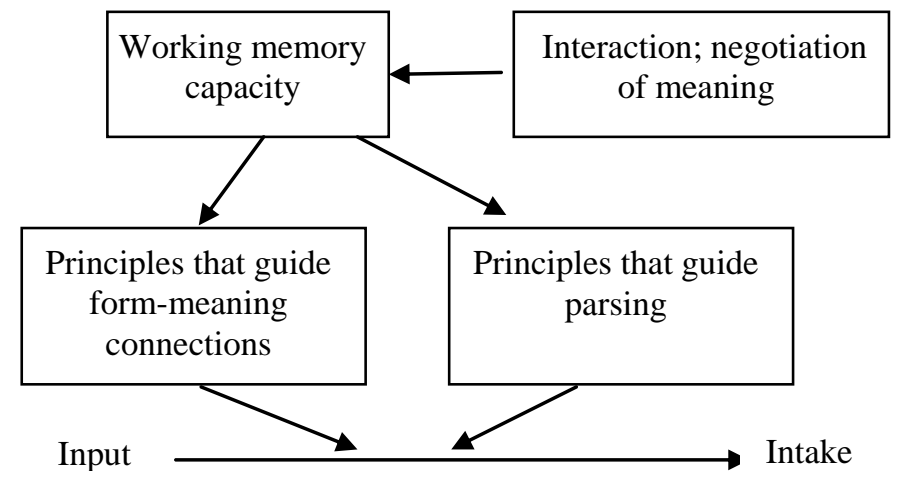

Fig. 1. Bill VanPatten's sketch of input processing

From Fig. 1, we can see even though interaction and negotiation of meaning cannot affect the principles of input but it has an impact on working memory, which plays an important role in the transformation from input to intake.

\section{Select Proper Language Learning Resources}

The informationalization of education contributes to the modernization and diversification of teaching and learning, which have been no longer restricted to textbook and teachers. Internet and learning platform on line 
has provided lots of resources for English leaning. The popularity of computer, mobile phone, MP3, MP4, etc. expands the scope and domains of English learning, which also make English learning interesting, practical, valid and convenient.

In our university, students have enjoyed multiple language learning resources. They have access to computer lab, library and most of them have had multimedia information equipments, such as computer, mobile phone, MP. Also, they are provided the learning platform of New Era interactive English, on which students are provided with various authentic English language material from English Speaking environment, such as video, articles, conversations. In addition, they have textbook --- New Horizon College English, Intensive Reading and Listening, which are designed according to topic system involving global culture and phenomena, human science, life, education, social problems and so on.

But facing with the learning material flood, how to organize and use them is a matter of debate. Therefore, the main purpose of the research is to organize the related information and combine multiple information resources systematically. Firstly, we carefully selected and established the theme of every unit according to the content of students' textbooks and students' interests and needs based on the results of our discussion and students' questionnaires. The topics are concerning social life, culture and present world affairs, and involving sense of value, emotion, daily life and education, which can broaden students' horizon, provide food for thought, and inspire their imagination. The topic should cause their interests and let them have desire to learn and exchange their ideas, which makes the language learning meaningful and interactive.

And secondly, centering the theme, some videos, listening materials, articles, and referred websites are collected. But it doesn't mean we just list lots of materials. One principle of material selection is themerelated and meaning-bearing. Meanwhile, a certain language characteristics, such as sentence patterns, expressions, grammar rules, should be highlightened to establish structured input. For example, under the topic "dream and ambition", the materials should embrace a flood of sentences of subjunctive mood, which will help students acquire the language phenomenon when they communicate with the materials, classmates and teachers about the topic. The two principles are to help learners make form-meaning connections and parsing.

Then, upload the materials to some shared platform such as QQ Zone, Weblog, interactive platform, public mail box, their mobile phone, and assign tasks to students to solve some problems referring to the materials that provided by teachers and found by themselves. Finally, collect and modify all the materials found by teachers and students and summarize the main language points and opinions about the theme.

\section{Input and Output Enhancement through Theme-oriented Teaching Mode}

In virtue of multi-media, the resource-based and theme-oriented English teaching mode is conducted to enhance the input of meaning-bearing language and create meaningful communicative environment to reinforce students' practical language ability, communication skills and inspire students' interests in English and their human quality. To achieve the aim, in addition to the sea of theme-oriented materials and information presented to students, some concrete measures were taken in practical teaching to guarantee the effective input of English language and smoothly running of teaching activities.

\subsection{Aiming at the cultivatng multiple intelligence, organize studying and interactive activities}

English learning is not only the study of language knowledge but the understanding of meaningful utterance and the cultivation of language ability. Theme-oriented English teaching mode is to enhance language input and intake and improve multiple intelligences by organizing proper study activities and designing multiple studying tasks. Students are organized into fixed groups to conduct cooperative study. When beginning a new unit, teacher will give a brief introduction to the theme of the topic and show students several video episodes to stimulate students' interests in the topic and give them clues for further thought by asking questions. With a group task for each group, students are assigned to study and search for the 
information at their will to complete the group task. And they have to discuss and negotiate with each other to prepare for classroom activities. In classroom, students are given most of the classroom time to exchange their opinions and conduct presentations. Different cooperative learning strategies can be employed according to different topics.

The teaching activities are designed referring to Gardener's theory of multiple intelligences [10]. Increase meaningful language input and cultivate diverse intelligences at the same time. How multiple intelligences are developed in the process of teaching is shown in Fig. 2.

In the figure, Column 2 is the teaching process, Column 2 is students' activities during the process, and Column 4 is Gardener's seven Multiple Intelligences. From the figure, we can see the seven intelligences are developed during the teaching process. In fact, Gardener added more types of intelligences, such as Naturalist, Spiritual / Existential, Moral [11], which are also the purposes of our teaching. Students also can cultivate their environmental awareness, ethics, humanity, and value of life. Especially, in the teaching mode, students have access to massive information and can have lots of channels to obtain information; therefore, their information quality will be improved during filtering information and making a decision.

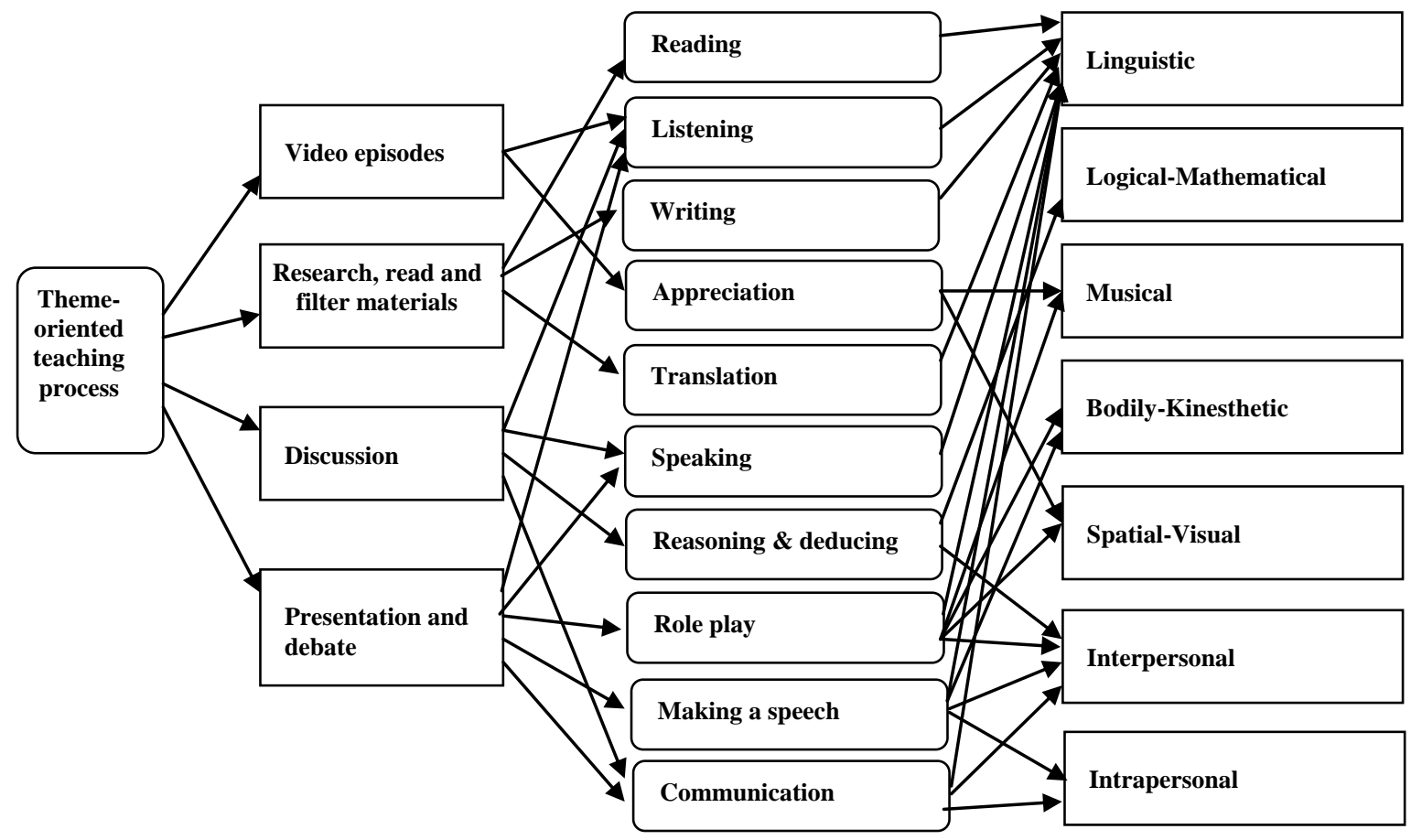

Fig. 2. Developing Multiple intelligences during teaching

\subsection{B. Theme-oriented English teaching can create input flood to enhance structured input.}

What is input flood? Wynne Wong illustrates it like this, "in language teaching, if we want our learners to notice a particular feature of the target language, we could flood the input with that particular linguistic feature. This technique is known as input flood [12]." The frequent appearance of a certain target feature can force learners to notice it and acquire it without teacher's explanation. Of course, it's no enough to create input flood and input processing is necessary for structured input. To complete the structured input of 
language structure and meaning, learners must experience a must process: recast --- confirmation check --clarification requests. Theme-oriented activities offer students lots of opportunities to complete the process.

Because theme-oriented English teaching focuses on a topic and students are exposed to flood of related materials, the emergence frequency of some language feature and related word and expressions will be rather high in the interactive activities, which can make form-meaning connections correctly and more efficiently. The content words which carry the most meaning related to the theme will be repeated many times. By means of that, the explicit accommodation will develop slowly into implicit knowledge. The output has a close relationship with implicit knowledge. Output is to exhibit students' explicit knowledge and tacit knowledge. In other words, when students

\section{Conclusions}

The research reveals multi-media resources, used as teaching resources, provide teachers and students massive authentic meaningful language input and facilitate teacher-student and student-student interaction. Students being the center of learning, the theme-oriented English teaching mode can arouse students' interests in English learning, develop their autonomous learning ability, cultivate their sentiment and improve their practical language ability.

\section{References}

[1] Van der Geer Cai Jigang, “About the reorientation of college English teaching”, Foreign Language Teaching and Research, 2010, vol. 42, pp. 306-308.

[2] Vygotsky, http://www.kidsdevelopment.co.uk/VygotskySocioCultural Theory.html.

[3] S. Krashen, "The input hypothesis", London: Longman, 1985. pp. 2 - 31.

[4] M.Swain, Communicative competence: some roles of comprehensible input and comprehensible output in its development”, Input and Second Language Acquisition, Eds. S. Gass and C. Madden. Rowley, Mass Newbury House, 1985.

[5] Vygotsky, http://portal.unesco.org/education/en/ev.php- URL_ID=26925\&URL_DO=DO_TOPIC\&URL _ SECTION=201.html.

[6] Wang Lifei, in W. Wong's book, "Input enhancement --- from theoy and research to the classroom", Beijing: World Publishing Corporation, 2007, pp.D14-15.

[7] W. Wong's book, "Input enhancement --- from theoy and research to the classroom", Beijing: World Publishing Corporation, 2007, pp.7.

[8] R. Ellis, "Understanding second language acquisition", Shanghai : Shanghai Foreign Language Education Press, 2003, pp. 262.

[9] B. VanPatten, "From input to output --- a teacher's guide to second language acquisition", Beijing: World Publishing Corporation, 2007, pp.51.

[10] H.F.Silver, R.W.Strong, M.J. Perini, "So each may learn:integrating learning styles and multiple intelligences", Beijing: Educational Science Publishing House, 2003, pp.4-9.

[11] W. Wong's book, "Input enhancement --- from theoy and research to the classroom", Beijing: World Publishing Corporation, 2007, pp. 45. 